\title{
Colônia do Pinhal: a fundação (1850-1857), Itaara-RS*
}

Pinhal's Colony: the foundation (1850-1857), Itaara-RS

Adriano Sequeira Avello** adrianos.avello@gmail.com

Jorge Luiz da Cunha*** jlcunha11@gmail.com.

Resumo: Durante a segunda metade do século XIX, período da imigração e colonização alemã no Rio Grande do Sul migraram colonos das antigas colônias para novas áreas de colonização atraídos também pela oferta da terra iniciada pela Lei de Terras de 1850. Neste contexto que surgiu na região denominada Pinhal, onde atualmente é o município de Itaara, Rio Grande do Sul - a Colônia do Pinhal. Apresentaremos "a fundação" da colônia agrícola afirmando o início do povoamento do município de Itaara através dos colonizadores alemães. Assim, problematizamos as (des)conexões entre a Colônia do Pinhal e a Colônia de Santa Maria da Boca do Monte evidenciando a complexidade geográfica da localização do Pinhal, bem como a identificação dos próprios organizadores, respectivamente, Miguel Kroeff e Phillip von Normann. Assim, o intuito é perfazer não só um debate sobre a aproximação e afastamento entre as Colônias do Pinhal e Colônia de Santa Maria da Boca do Monte, mas também esclarecer os possíveis empreendedores, respectivamente, Miguel Kroeff ou Phillip von Norman. Como desenlace disto se terá a busca de uma data para fundação da Colônia do Pinhal.

Palavras-chave: imigração alemã, Colônia particular, migração

Abstract: During the second half of the nineteenth century, period of immigration and german colonization in Rio Grande do Sul settlers migrated from the former colonies to new areas of colonization attracted by the land caused by the Land Law of 1850. It is in this context that emerged in the region called Pinhal, where is now the county of Itaara, Rio Grande do Sul - the Pinhal's Colony. The workstandsoutfrommigrantstosubtropicalforest areaofPinhal forest, driven by commercialization oflandwithin thesettlement. Then, we presentthe foundation"of theagricultural colonystatingthe beginning ofItaaracounty ofsettlementthrough thegerman settlers. So will problematize the (dis)connections between the Pinhal's Colony and the Santa Maria da Boca do Monte's Colony showing the geographic complexity in Pinhal, as well as the location and identification of the organizers themselves, respectively, Miguel Kroeff and Phillip von Normann. So, we investigated the foundation and organization of the colony in order to score a date, as historiography seen so far is not precise on the establishment of the colony.

Keywords: German immigration, Particular colony, migration

*Mestrando em História pelo Programa de Pós-Graduação da Universidade Federal de Santa Maria (UFSM). Bolsista CAPES/DS.

**Professor do Programa de Pós-Graduação em Educação e do Programa de Pós-Graduação em História da Universidade Federal de Santa Maria (UFSM). 
Chegarmos a uma verdade que sempre será distinta da verdade que poderíamos qualificar como definitiva. Essa é a característica da comunicação dos historiadores. Sempre trabalhamos sobre algo que não se pode afirmar inquestionavelmente, que não se pode resolver definitivamente.

Giovanni Levi (2014, p. 5)

A migração interna na Província do Rio Grande do Sul seria dinamizada muito em decorrência pela vigência da Lei n. 601 de 18 de setembro de 1850 conhecida como Lei de Terras de 1850, executada pelo Decreto n. 1.318 de 30 de janeiro de 1854, a qual permitia o governo provincial vender terras públicas. A lei movimentou imigrantes alemãesque estavam assentados ou já em constantes deslocamentos de um lugar para outro na busca por novas terras. Em torno desta migração espontânea surge a organização de umacolônia particular denominada Colônia do Pinhal, atualmente corresponde ao município de ItaaraRS.Brenner (2007) denomina os primeiros colonizadores como as famílias pioneirasas quais iniciaram o assentamento nas terras do Pinhal: de Miguel (Michael) Kroeff, Jacob (Jacó) Albrecht e Jacob (Jacó) Adamy. Contudo, organização da Colônia do Pinhal há aproximação territorial e temporal da Colônia de Santa Maria da Boca do Monte necessitando que assim se problematize tais (des)conexões entre ambas até evidenciação de uma data para fundação da colônia.

\section{A Colônia Kröeff por Miguel Kroeff}

A Colônia alemã do Pinhal foi organizada "pelos alemães Jacob Albrecht, Jacob Adami e Miguel Kroef" que "em sociedade adquiriram terras no Pinhal” (BELÉM, 2000[1933], p. 188). Contudo, a "Sociedade Colonizadora" para compra de terras da Colônia segundo afirma Brenner era "formada por Miguel Kroeff e Johann Jacob Albrecht" apenas e não incluiria Adamy (BRENNER, 2007, p. 2). Em outro texto reitera Brenner que Miguel Kroeff juntamente "com Jacob Albrecht formou a Sociedade Colonizadora que adquiriu a área para estabelecer a colônia"2. E, ainda, que Jacob Albrecht "comprou as terras, no Pinhal, associado a Miguel Kroeff, e também em seu próprio nome estando já ali estabelecido, no início de 1857". 3

Aqui se encontra uma das muitas divergências que gerarão incertezas sobre alguns aspectos sobre a história da Colônia do Pinhal e as explicações poderão vir, apenas, quiçá, no futuro com novas pesquisas históricas, haja vista no dizer de Mattoso (1988, p. 26) "a dificuldade da tarefa estimula muitas vezes a perspicácia da busca". Sendo assim, salienta-se:

O trabalho histórico transforma-se então em desporto, numa autêntica aventura exploratória, quando não numa tarefa de detective. Encontradas as pistas, apanhada a caça, detectado o responsável, é preciso demonstrar o que se descobriu, fazer os relatórios, passar à fase da escrita, da comunicação. É preciso transmitir o que se encontrou. Têm de se distribuir os tesouros desenterrados (MATTOSO, 1998, p. 26).

O que se pode asseverar no momento não são quais imigrantes participavam da Sociedade Colonizadora, mas a própria criação e existência de tal associação, porque conforme Ruppenthal (2000, p. 10) explica:

\footnotetext{
${ }^{1}$ A "Sociedade Colonizadora" é denominada por Brenner, todavia o autor não apresenta uma fonte sobre assunto; esse tema ainda carece de pesquisas. Apenas temos indícios apontados pela bibliografia, os quais corroboram em parte com o autor. Entendemos que Sociedade Colonizadora diz respeito a uma "empresa" no sentido de acordo de negociação para compra de terras em conjunto. Diferentemente das empresas colonizadoras que estavam no estado que tinham um porte maior com investimentos de capitais até mesmo internacionais como, por exemplo, a companhia judaica francesa Jewish Colonization Association (JCA). Nesse sentido tal temática carece de mais pesquisa.

${ }^{2}$ BRENNER, José Antonio. Os 150 anos da Colônia Pinhal. Jornal A Razão, Santa Maria, 21 de maio de 2007, p. 6.

${ }^{3}$ BRENNER, José Antonio. As famílias pioneiras do Pinhal. Jornal A Razão, Santa Maria, 21 de maio de 2007, p. 7.
} 
Todos os indícios revelam que, igualmente pela quantidade de pessoas envolvidas no empreendimento, houve planejamento anterior à ocupação. Esta visão, se for considerada a época, a natureza do empreendimento e também a forma de aquisição das terras destinadas aos assentamentos, apontam a interferência da formação de uma espécie "sociedade" cuja ideia, originou -se de perspicaz observação, conforme consta e pode ser interpretado do "Relatório de Felipe de Normann” (1858).

De acordo com Brenner "Miguel Kroeff foi o líder empreendedor da Colônia Alemã do Pinhal"4. Aqui o elemento que passa a nos guiar a procura de qual colono teria sido o organizador da Colônia é "aquilo que distingue um indivíduo de um outro em todas as sociedades conhecidas: o nome. A utilização do nome para abrir novos campos à investigação histórica" (GINZBURG; PONI, 1989, p. 174). Neste sentido, percebe-se a liderança de Kroeff perante a comunidade alemã do Pinhal quando a Câmara Legislativa de Santa Maria, em Sessão do dia 09.07.1861, convoca o colono alemão a comparecer futuramente, então:

Foi lido um officio da Prezidencia da Provincia, sob $n^{o} 11$ de 22 de Junho findo, ordenando que a Camara informe se convem crear-se um Districto de Pás na Colonia particular estabelecida por Miguel Kroeff, visto conter os prasos, pagos, familias, e numero de almas constante do relatorio aprezentado pelo mesmo Kroeff, prevenindo que a mesma data officiou-se ao Doutor Chefe de Policia acerca da creação, de um Districto Policial, e finalmente que se mande proceder aos necessarios exames $e$ orçamento das composturas das estradas da mesma Colonia, que, segundo o mesmo relatorio, dellas carecem; resolvéo a Camara Officiar ao referido Miguel Kroeff, a fim de que se aprezente á esta Camara nas prezentes Sessões, afim de dar os esclarecimentos que são mister, para satisfazer-se á Sua Excelência. $^{5}$

\section{Miguel Kroeff sendo o principal} organizador da Colônia do Pinhal, às vezes, tem a colônia considerada como propriedade sua a Kolonie Kroeff (KADLETZ in FISHER, 2005, p. 173). Aquele foi um "homem de muitas iniciativas, sua liderança era de tal forma reconhecida que, num mapa de 1885, a Colônia do Pinhal consta como 'Kröff', na forma

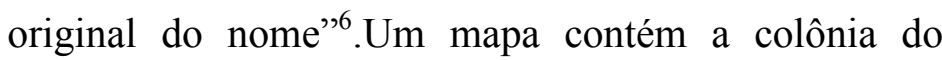
Pinhal com a nomenclatura de (Colônia) Kröff (sic).O mapa se encontra no capítulo sobre Robert AvéLallemant em Marchiori e Noal Filho (1997, p. 48) os autores esclarecem que o mapa foi extraído da obra Der Auswanderer: Winke und Weisungen für Unsiedler in den deutschen kolonien Süd-Brasiliens, de August von Eye, publicado em Berlim, Alemanha, 27 anos após a visita de Avé-Lallemant, em 1858. Acerca da Colônia do Pinhal as compras das terras:

A maior parte era a 'Estância Pinhal', do Tenente-Coronel João Baptista de Oliveira Mello, cuja sede ficava $12 \mathrm{~km}$ ao norte, e no Arroio Pinhal, havia uma serraria movida a roda-d'água, pertencente a Manoel Alves Pereira. Para estabelecer a colonia alemã, e 1857, as terras foram compradas principalmente desses dois proprietários, mas também de outros menores, como José Cezar da Silva. ${ }^{7}$

A planta ${ }^{8}$ sobre as medições da colônia alemã elaborada pelo agrimensor Gustav von

\footnotetext{
${ }^{4}$ BRENNER, José Antonio. Os 150 anos da Colônia Pinhal. Jornal A Razão, Santa Maria, 21 de maio de 2007, p. 6.

${ }^{5}$ Livro I de Atas (1858-1864) - ACMVSM. fls. 107v; 108; e 108v.

${ }^{6}$ BRENNER, José Antonio. As famílias pioneiras do Pinhal. Jornal A Razão, Santa Maria, 21 de maio de 2007, p. 7.

${ }^{7}$ BRENNER, José Antonio. Os 150 anos da Colônia Pinhal. Jornal A Razão, Santa Maria, 21 de maio de 2007, p. 6.

${ }^{8}$ A planta representa uma área pequena e com pormenores descritos. Diferente de mapa que abrange um espaço territorial maior ver mais em: BRENNER, José Antonio. Pinhal - 150 anos - Itaara. Folheto 4f. [s.1.]: [s.n], [2007].Não tivemos acesso ao documento original contido arquivo pessoal de José Antonio Brenner.
} 
Normann ${ }^{9}$ apresenta as medições das terras do Pinhal compradas por Miguel Kroeff, Jacob Albrecht e Jacob Adamy:

Em abril e maio de 1857, foram medidas as terras de Jacob Adamy, compradas no ano anterior. A área de 676 hectares, quase toda coberta por araucárias, corresponde, em grade parte, ao atual núcleo urbano de Itaara, a leste da Avenida Guilherme Kurtz que, na época, era a Estrada Geral. As terras lindeiras, ao norte, leste e sul, pertenciam à Sociedade Colonizadora, formada por Miguel Kroeff e Johann Jacob Albrecht. Esses dois pioneiros também tinham suas terras particulares a oeste da Estrada Geral e na margem direita do Arroio Pinhal (BRENNER, 2007, p. 2).

De acordo com Weimer (2006, p. 155) a planta cartográfica que Gustav von Normann produziu sobre a Colônia era um trabalho "contratado por João Miguel Adamy (Adami) que adquirira terras no Pinhal para fundar uma colônia que seria ocupada por colonos alemães", pois, "o mapa por ele assinado e avalizado por seu irmão Phillip demonstra a localização de 676 hectares de terras em local hoje centralizado pelo núcleo urbano deItaara". Entende-se que Adamy seria um dos fundadores, contudo não participa da empresa ${ }^{10}$ Sociedade Colonizadora.

O que procede quando Belém (2000 [1933], p. 188) afirma que "medido o terreno, divido em lotes, foram uns arrendados, outros vendidos e a maior parte cultivados pela própria empresa". Os lotes vendidos e arrendados a partir das três famílias pioneiras (Kroeff, Albrecht e Adamy) e pela Sociedade colonizadora (Kroeff e Albrecht) foram colonizados pelas famílias "Gehm, Zimmerman, Bopp, Schreiner, Streccius e Ilges" que migraram "de antigas colônias alemãs de Campo Bom, Picada 48, em Ivoti, Estância Velha e Porto Alegre" $"$. Haja vista que a Colônia do Pinhal foi uma colônia particular de proprietários, como Sociedade Colonizadora, todavia incipiente, não chega a tornar-se uma colônia de empresa ou companhia de colonização. O que não impediu que se aproveitassem da elevação do preço das terras para comercializa-las. Provavelmente a Sociedade Colonizadora continhauma administração autônoma, por assim dizer, entretanto não fica esclarecido se há uma sede administrativa. Logo, sendo uma colônia particular não recebe amparo financeiro do Governo Imperial ou Provincial para suporte com ferramentas e sementes em casos de perdas da colheita.

Atentamos até o momento para Miguel Kroeff, Albrecht e Adamy como os organizadores da Colônia do Pinhal. Porém, destacamos no estudo de Ruppenthal (2000) o "Relatório de Felipe de Normann" que explicaria a ocupação e a forma de "sociedade" no Pinhal e, novamente, na confecção da planta cartográfica feita pelo agrimensor Gustav von

\footnotetext{
${ }^{9}$ Gustav Adolf von Normann nascido a 08.03.1831 em Neuhof bei Brandhagen, filho de Karl Wilhelm von Normann e Wilhelmine Wichmann, foi um construtor alemão. Chega a Porto Alegre, em 1848, com os dois irmãos: Axel Friedrich Wilhelm, nascido em 25.02.1829 e Georg Karl Phillip Theodor, nascido em 23.02.1818, que se tornou importante arquiteto em Porto Alegre. Há menção de haver um terceiro irmão de nome Reinhold. Os irmãos deslocaram-se para Santa Cruz onde seriam colonos. Gustav von Normann esteve estabelecido em Santa Maria, em 1857, quando também residia seu irmão Phillip von Normann. Nas proximidades de Santa Maria foi contratado para desenhar o mapa da compra de terras no que viria a ser uma colônia alemã ocupada por colonos - Colônia do Pinhal. Posteriormente, mudou-se para Porto Alegre onde trabalhou na Repartição de Obras Públicas como "desenhador" juntamente com o irmão Phillip. O relatório Presidencial de 1867 informa que fez outros trabalhos como a planta da Fazenda dos Prazeres e levantamento dos arroios Sutil e Douro. Enquanto fazia estes trabalhos exercia docência no Liceu Dom Afonso ministrando aulas de Desenho em dupla com Maximilian von Emmerich, professor de Desenho da Escola Militar. Após a saída do magistério volta a Santa Cruz para ajudar o irmão Phillip que passava por dificuldades. Em Porto Alegre, casa-se em 05.01.1863, com Catarina Ruperti, todavia o matrimônio não deu certo. Mesmo com um filho Ernst, recém-nascido, alista-se para combater na Guerra do Paraguai. Em 1875, no inventário do sogro, a esposa relata que o esposo está ausente, e em lugar incerto, há cinco anos. Anos mais tarde o filho encontrou-o, mas não deixou registrado o local (WEIMER, 2006).

${ }^{10}$ Nos referimos a Sociedade Colonizadora como empresa devido a associação entre Kroeff e Albrecht após comprar as terras loteá-las em colônias ter interesse em lucrar com a colonização oportunizada pela Lei de Terras.

${ }^{11}$ BRENNER, José Antonio. O Sesquicentenário do berço de Itaara. Jornal A Razão, Santa Maria, 14 de novembro de 2007, Caderno Segundo A Razão, [s.p.].d
} 
Normann, apresentada por Brenner (2007). Temos ainda o destaque dado por Weimer (2006) que "Phillip", irmão de Gustav, garantiria a validade da planta. Assim, constatamos pela análise micronominal que "o fio condutor é, mais uma vez, o nome" conforme destaca Ginzburg e Poni (1989, p. 175). Pois, foi através de "Felipe de Normann" forma aportuguesada do nome de "Phillip von Normann"12 que conseguimos identificar a aproximação com a Colônia do Pinhal.

\section{A Colônia de Santa Maria da Boca do Monte por Phillip von Normann}

Ao referir-se a personalidades da imigração alemã Cunha (2004b, p. 110) destaca que "dignos de lembrança são também os engenheiros, agrimensores cartógrafos contratados pelo governo provincial, como Georg Karl Philip von Normann (1818-1862) que atuou em quase todo o Rio Grande do Sul, registrando em cartas cartográficas nosso território". Weimer (2006, p. 147) diz que Phillip von Normann "foi contratado pelo governo provincial para administrar a compra e a distribuição de ferramentas destinadas a cada colono. Manteve-se, nesta função até meados de 1851”. Em 1848, o primeiro trabalho que recebeu do governo provincial era desenhar a carta geográfica da Província que ficou inacabada. Já 1850, refez o projeto do Teatro São Pedro, em Porto Alegre, cujas obras haviam sido interrompidas devido o início da Guerra dos Farrapos.
O projeto agradou o governo e Phillip von Normann seria contratado como efetivo da Secretaria de Obras da Província para realizar os projetos maisimportantes da Repartição como: o Liceu Dom Afonso, em parceria com o arquiteto Friedrich Heydtmann; a Câmara da capital; a conclusão da Igreja do Menino Deus; a Casa de Caridade e a cadeia de Rio Grande; a Câmara de Jaguarão entre outras obras pelo interior da Província. ${ }^{13}$ Após a breve contextualização sobre a vida de Phillip von Normann nos deteremos em seus Relatórios para investigar qual a origem da Colônia do Pinhal. Sendo que o primeiro relatório é referente a um Mapa estatístico, territorial e agrícola da Colônia de Santa Maria da Boca do Monte - $1858^{14}$ e demonstra aproximações com os colonos do Pinhal porque contém os nomes dos respectivos colonos do Pinhal juntamente com a extensão da terra comprada e os tipos de plantação agrícola que estava desenvolvendo.

O Mapa estatístico, territorial e agrícola da Colônia de Santa Maria da Boca do Monte que relata entre os proprietários os povoadores da Colônia alemã do Pinhal apresenta na sua coluna, à esquerda, o nome dos 26 colonos proprietários e o município a que pertencia a propriedade assim conseguimos reconhecer apenas 7, respectivamente: Jacó Albrecht/Cruz Alta, Miguel Kroeff/Cruz Alta, Jacó Adami Filho/Cruz Alta, Daniel Gehm/Cruz Alta, Jacó Adami/Cruz Alta, Martinho Zimmermann/Cruz Alta e Pedro Schreiner/ Cruz Alta.

\footnotetext{
${ }^{12}$ Georg Karl Phillip Theodor von Normann nascido a 23.02.1818, em Halle, Alemanha, filho de Karl Wilhelm von Normann e Wilhelmine Wichmann, foi um reconhecido arquiteto alemão. Não há informações sobre a formação profissional, mas os documentos indicam ter sido nível superior. Iniciou a vida profissional como construtor de ferrovias nas minas de Hoganas, na Suécia. De lá era originaria sua esposa Maria Ablström,com a qual casou-se em 12.09.1844, em Friburgo, no Rio de Janeiro. Em 16.05.1856, divorcia-se da mesma na paróquia evangélica de Porto Alegre, conforme documenta o registro eclesiástico do pastor Erdmann Georg Richard Ernst Wolfram e registrado no cartório civil por Marcos Alves Pereira Salgado, fato singular da justiça brasileira no período Imperial. Chega em Porto Alegre, em 1848, com os dois irmãos Axel Friedrich Wilhelm, nascido em 25.02 .1829 e Gustav Adolf von Normann nascido a 08.03.1831 em Neuhof bei Brandhagen. Há um outro possível irmão que atenderia pelo nome de Reinhold von Normann. Iriam exercer a profissão de colonos em Santa Cruz. Casou-se, ainda, pela segunda vez, com Margarida de Sá Brito, 06.08.1859 na Igreja Católica, já que von Normann era protestante (WEIMER, 2006).

${ }^{13}$ Para uma detalhada informação sobre as obras de arquitetura e engenharia efetuadas por Phillip von Norman ver WEIMER, Günter. Georg Karl Phillip Theodor von Normann. In:___ . Arquitetos e construtores do rio-grandenses na colonia e no império. Santa Maria: Ed. da UFSM, 2006, p. 146-154.

${ }^{14}$ Colonização. Mapa estatístico, territorial e agrícola da Colônia de Santa Maria da Boca do Monte - Relatórios de Felipe de Normann - 1 de maio de 1858. AHRS - caixa 35 - maço 65.
} 
Fica-se com as seguintes indagações: 1) porque os colonos do Pinhal estão presentes na dita Colônia de Santa Maria da Boca do Monte 2) com a propriedade pertencendo a Cruz Alta e não a Santa Maria a que se refere o título do mapa? 3) Seria a Colônia do Pinhal a mesma Colônia de Santa Maria da Boca do Monte ${ }^{15}$

Alguns indícios nos direcionam para situação dos arquitetos e engenheiros funcionários que prestavam serviços ao governo da Província com relatórios sobre a situação territorial, agrícola e demográfica dos "núcleos coloniais germânicos" para o governo estar inteirado da produção econômica das colônias alemãs e do estado organizativo que se encontram. Quando trata de "Santa Maria da Bocca do Monte" Pellanda (1925, p. 175) explica que "os dados" sobre uma "colônia no Pinhal" estavam disponíveis no relatório do presidente da província Angelo Moniz da Silva Ferraz de 1858: "Das informações a que mandei proceder pelo engenheiro Felippe de Normann e respectivo sub-delegado de polícia, consta actualmente sua população de 139 pessoas, residindo $76 \mathrm{em}$ terras que pertencem ao município de Santa Maria e 63 ao de Cruz Alta". Houve provavelmente um recolhimento demográfico das "propriedades" de colonos alemães com as respectivas famílias no âmbito rural entre Santa Maria e Cruz Alta. Os números de residentes tanto de Santa Maria como Cruz Alta são elevados e não constam diretamente no relatório, porque o número total de (26) proprietários é determinada no relatório. O que só realça a possibilidade de inclusão das famílias na contagem demográfica. A inclusão dos colonos do Pinhal pertencendo ao município de Cruz Alta sugere o entendimento de que as propriedades daqueles tinham uma grande extensão que atingiria até o município de Cruz Alta. Ou as dificuldades de indicar com exatidão a zona limítrofe está relacionada a constante evolução político-administrativa dos territórios limítrofes no período imperial, no que tange aos limites municipais, no caso, da região central.

Quanto a Colônia do Pinhal ser a mesma Colônia de Santa Maria da Boca do Monte nos traz certas dúvidas devido a certas similaridades como: os de localização conflitante e ambígua sobre a Colônia particular do Pinhal e os colonos do Pinhal "aparecem" em alguns documentos ${ }^{16}$ e bibliografias. Isto, de certa forma, é recorrente na temática de imigração e colonização segundo explicam Giron e Bergamaschi (1996, p. 30) sobre as pesquisas das colônias particulares
"Muitos autores confundem-nas com as do período posterior. Os estudos são vagos e apenas descritivos, são mais citadas do que estudadas. Outra dificuldade para o estudo é o fato de que muitas mudaram de donos, passando do império para iniciativa privada e, passando dessa, para o poder público".

Nesta esteira, sublinhamos aproposta do Relatório de Felipe de Normann - 1 de maio de $1858^{17}$ a qual envolve-se, no nosso entender, em muitas dúvidas. Se por um lado Phillip von Normann conforme demonstramos, anteriormente, fez o relatório em 1858 a pedido do presidente da Província Angelo Moniz da Silva Ferraz descrevendo a Colônia de Santa Maria da Boca do Monte ${ }^{18}$ com um Mapa estatístico, territorial e agrícola e um Mapa estatístico da

\footnotetext{
${ }^{15}$ Mesmo se considerarmos que Pinhal, no século XIX, pertencia a Júlio de Castilhos, ex-Vila Rica, que por sua vez, pertencia a Cruz Alta. Ainda é pertinente sanar as dúvidas em relação a Colônia de Santa Maria da Boca do Monte e a Colônia do Pinhal.

${ }^{16}$ Colonização. Mapa estatístico, territorial e agrícola da Colônia de Santa Maria da Boca do Monte - Relatórios de Felipe de Normann - 1 de maio de 1858. AHRS - caixa 35 - maço 65.

${ }^{17}$ Colonização. Relatório de Felipe de Normann - 1 de maio de 1858. AHRS - caixa 35 - maço 65. Transcrevemos o documento na intenção de preserválo para futuras pesquisas, pois o mesmo encontra-se com muitas partes danificadas devido às intemperes do tempo, ver Anexo 3.

${ }^{18}$ Observamos que na abertura do maço 65 tem uma folha do arquivista que diz: "S/d. Colônias nos municípios de Santa Maria da Boca do Monte e Cruz Alta. Minuta de informação". Colonização. Mapa estatístico, territorial e agrícola da Colônia de Santa Maria da Boca do Monte - Relatório de Felipe de Normann - 1 de maio de 1858 . AHRS - caixa 35 - maço 65.
} 
população ${ }^{19}$ conforme os dados mostrados por Pellanda (1925, p. 175-176). O que necessita reexaminar a fonte de Pellanda porque estão conflitando as informações. E por outro lado aquele documento que nos referimos no início apresentaria uma Proposta ${ }^{20}$ aos moldes de uma colônia particular de empresa, de acordo com a Condição $1^{\text {a }}$, da proposta:

$O$ proponente obriga se comprar do Governo Provincial quatro léguas quadradas ou huma aria e quinhentos de terras devolutas, das de que texta a Lei Geral de 28 de Outubro de 1848 Capitulo $3^{\circ}$ Artigo 16, e sitas na Serra Geral, no Distrito de São Martinho, sobre as cabeceiras do Arroyo Grande, tributário do Arroyo Vacacahy mirim, para coloniza-las, estabelecendo nellas, e pelo [ilegivel], cento e vinte famílias de quatro pessoas cada huma por termo médio, e na razão de uma família por cada secç̧ão de tresentos mil braças quadradas. Não ficará o proponente inhibido de estabelecer maior numero de familias nas ditas terras, nem de subdividi-las como mais lhe convir. ${ }^{21}$

O local na Serra Geral, no Distrito de São Martinho, sobre as cabeceiras do Arroyo Grande, tributário do Arroyo Vacacahy Mirim, nos parece imprecisa. Pois, não encontramos outros estudos que contemplassem tal assunto além do subcapítulo da dissertação de Nicoloso (2013, p. 43-46) A tentativa frustrada de implantação da colônia alemã na serra de São Martinho e da dissertação de Külzer (2005, p. 4647). A abordagem de ambos os pesquisadores são relevantes, mas não suficientes para nosso estudo, na Colônia do Pinhal. Pois, na análise documental que fizeram do relatório de Phillip von Normann não consideraram o indício geográfico e humano, porque apresentam a serra de São Martinho como uma região vasta demais, isto é, sem precisão local. Devido a esta imprecisão local subentende-se que os colonos do Pinhal "pertenceriam" a tal Colônia de Santa Maria da Boca do Monte.

De acordo com Nicoloso (2013, p. 43) "agentes particulares da imigração" fizeram “investidas no sentido da implementação de uma colônia alemã com características agrárias na região. A tentativa houve. $\mathrm{O}$ local escolhido para sua instalação foi a serra de São Martinho”. Assim, Phillip von Normann concebeu o projeto de estabelecer uma colônia de imigração particular alemã na Serra Geral:

Felippe Normann em 1856, explorando
os matos na região de Santa Maria
concebeu o projeto de estabelecer uma
colônia de imigração alemã, no alto da
Serra Geral, por iniciativa particular.
Em 1858 envia à Presidência da
Provincia um relatório revelando a
situação da suposta Colônia, na
expectativa de auxilio governamental,
para 32 familias alemãs ou teuto-
descendentes (que, em sua maioria,
afluiam da Colônia de São Leopoldo).
Estes alemães começaram a migrar para
Santa Maria, atraídos pela
disponibilidade de terras devolutas
(KÜLZER, 2005, p. 46, grifo nosso).

Conforme sinalizado a organização de uma colônia alemã com características agrárias na região apenas nos remete para a Colônia do Pinhal quando Nicoloso (2013, p. 32) destaca “a tentativa fracassada de implementação de uma colônia particular na serra do Pinhal”. E, ainda, Nicoloso e Cunha (2012, p. 325, grifo nosso) notificam que:

Por volta dos anos 1870, houve a
tentativa da implantação de uma Colônia
Particular na região de Santa Maria
que hoje é conhecida como Pinhal, mas
não teve sucesso em função de diversos
problemas, como a falta de organização

Por volta dos anos 1870, houve a tentativa da implantação de uma Colonia Particular na região de Santa Maria que hoje é conhecida como Pinhal, mas problemas, como a falta de organização

\footnotetext{
${ }^{19}$ Colonização. Mapa estatístico da população da Colônia de Santa Maria da Boca do Monte - Relatório de Felipe de Normann - 1 de maio de 1858 . AHRS - caixa 35 - maço 65. Esta fonte não foi utilizada em nosso Trabalho de Conclusão de Graduação (TCG).

${ }^{20}$ Não nos cabe analisar uma a uma das condições, mas sim uma síntese da proposta feita por Phillip von Norman. Porque nosso interesse diz respeito a "aproximação" da Colônia do Pinhal com a Colônia de Santa Maria da Boca do Monte ao invés da viabilidade de execução desta.

${ }^{21}$ Colonização. Relatório de Felipe de Normann - 1 de maio de 1858. AHRS - caixa 35 - maço 65.
} 
dos empresários, falta de pessoal qualificado para os trabalhos iniciais que era preciso para a abertura de uma Colônia rural.

Uma Colônia Particular na região de Santa Maria sendo conhecida como Pinhal pode ser indício de que a colônia não levava o nome, no primeiro momento, de Colônia do Pinhal podendo ser a colônia de Santa Maria da Boca do Monte. Reiteramos como em Külzer (2005) reaparece uma colônia de imigração alemã de iniciativa particular no alto da Serra Geral, Serra de São Martinho, provavelmente como destaca a autora e Nicoloso (2013), visto que ao revisarmos a bibliografia sobre a região de Santa Maria não encontramos vestígios de imigração e colonização alemã em São Martinho da Serra. ${ }^{22}$

O que nos reforça a indagar sobre a possível relação entre as duas colônias. E, assim, como propõe Mattoso (1988, p. 25) "se inspirar também nos processos da imaginação e da perspicácia. É preciso dectecar as anomalias, fazer falar indícios mudos, acumular provas, inventar formas indirectas de revelar o que os documentos não dizem abertamente".

De acordo com a análise detalhada sobre a viabilidade da proposta de implementação da Colônia de Santa Maria da Boca do Monte, de Phillip von Normann, Nicoloso (2013, p. 45) conclui:

Pelo fato de a colonia ter sido fruto da iniciativa particular, acabou padecendo pela própria falta de investimentos. À época, Felipe Normann assumiu a frente dos negócios de uma sociedade por ele estabelecida, no objetivo de dirigir-se ao governo imperial "demonstrando" que tinha recursos para a realização de tal empreitada. $O$ projeto de Normann esbarrou na política da Coroa, que não deferiu a petição por ele encaminhada e, com isso, não vendeu à sociedade as terras devolutas que esta havia pedido para compra.

Segundo ensina Ginzburg (1989, p. 177) "se a realidade é opaca, existem zonas privilegiadas - sinais, indícios - que permitem decifrá-la. Essa ideia, que constitui o ponto essencial do paradigma indiciário ou semiótico". A partir disto compreendemos que a "Colônia de Santa Maria da Boca do Monte" é fictícia em si mesma, ou seja, existe apenas "no papel", nos Relatórios de 1858 Phillip von Normann. Contudo, os dados são reais, porque von Normann fizera um "apanhado" da região onde encontravam-se colonos alemães "dispersos", entre os municípios de Santa Maria e Cruz Alta, já estabelecidos nas terras e circundaria tal área de terras devolutas organizando para os novos colonos que viriam, e os antigos que ali estavam, o desenvolvimento do que denominou de "Colônia de Santa Maria da Boca do Monte".

A chance no negócio de tentar agenciar uma colonização provavelmente foi amadurecido no ano de 1857 quando Phillip von Norman está "residindo em Santa Maria e participou - pelo menos como testemunha - do levantamento que seu irmão Gustav Adolf fizera da Colônia do Pinhal" e executou o trabalho de fiscalizar "as obras da estrada de São Martinho a Pinhal, em Santa Maria" (WEIMER, 2006, p. 152). Quando avalizou a planta do irmão no reconhecimento legal na medição das terras do Pinhal, em 1857, percebe uma oportunidade de colonização na região de Pinhal e São Martinho da Serra, especulando terras - comprando e revendendo na variação dos preços no mercado, para fazer uma proposta de acordo

\footnotetext{
${ }^{22}$ CASSOL, Fabricio Tironi. São Martinho: da desestruturação político-administrativa do município aos reflexos econômicos na região. Santa Maria, Monografia (Graduação), Centro universitário Franciscano, 2012. SPOLAOR, Andréia Simone de O. A imigração russa-alemã na $4^{a}$ colônia de imigração italiana (1877-1890). Santa Maria, Monografia (Graduação), Centro universitário Franciscano, [s.d.]. BRENNER, José Antonio. Imigração Alemã: a saga dos Niederauer. Santa Maria: Ed. da UFSM, 1995.
} 
com o Relatório de 1 de maio de 1858. Este definia o desenvolvimento em colônia mista tendo por base, no caso, os colonos alemães do Pinhal, isto é, a Colônia do Pinhal. O interesse de von Normann na região do Pinhal era devido a elevação dos preços das terras na medida que a densidade demográfica aumentava. O que estava ocorrendo devido as migrações das antigas áreas coloniais de 1824 para Pinhal. Zarth (2002, p. 92) exemplifica detalhadamente este tipo de situação do Pinhal quando aborda comércio de terras no planalto gaúcho:

Os preços mínimos das piores áreas também evoluem, mas não na mesma proporção, o que é natural, pois são terras de precária utilização econômica. As terras de melhor preço no século XIX, considerando as condições técnicas do trabalho da terra eram: os campos com pastagens naturais e com boa água, e também matos com ervais e matos em geral, pois a agricultura praticamente se limitava a aproveitamento da fertilidade natural da floresta através do sistema de pousio longo. Esta última somente passou a ter preço considerável à medida que a densidade demográfica subia e, de forma especial, seus preços disparam quando começou o surto de colonização do Rio Grande, onde a densidade demográfica era muito elevada para o modelo de agricultura que se praticava.

Então, no mesmo ano de 1858 von Normann esteve em Santa Maria encarregou-se de outros trabalhos como o cemitério municipal, conforme Flores (2006, p. 96) demonstra:

Em 15 de maio de 1858, em uma terceira correspondência à presidência da Província, Gomes do Vale fez referência a planta do cemitério encomendada ao engenheiro Felipe Norman, e enfatizou mais uma vez a falta que a edificação do cemitério [em Santa Maria] fazia, afetando não somente a "salubridade pública, como a moralidade e o espírito religioso".

Embora aceita-se o trabalho da "construção do cemitério local [...] não teve condições de levar a obra contratada a bom termo, em razão do que seu contrato foi rescindido" (WEIMER, 2006, p. 152). A Colônia do Pinhal havia valorizado as terras na região, assim von Normann pediu o investimento do governo da província o que pela lógica da mercantilização da terra pelos agentes de colonização seria repassado com um valor reajustado aos colonos. A obtenção de lucratividade com o elevado preço das terras e os juros cobrados dos colonos nas vendas dos terrenos era forma de retroalimentar o sistema de especulação fundiária no pós Lei de Terras.

\section{Phillip von Norman em Santa Cruz "recebeu uma} gleba e um quarto de légua em quadra na estrada de Cima da Serra, em dezembro de 1850" o que lhe rendeu certa experiência em administrar colonização e, também, "pode ser justificado pelo fato de que, desde logo, foi contratado pelo governo provincial para administrar a compra e a distribuição de ferramentas destinadas a cada colono. Manteve-se, nesta função até meados de 1851" (WEIMER, 2006, p. 147). Sobre as terras recebidas por von Normann, Cunha $(1988$, p. $77-$ 78) explica que "nem mesmo Santa Cruz do Sul, fundada em dezembro de 1849 em Rio Pardo, [...] foge do assédio dos especuladoresque têm suas posses confirmadas por títulos distribuídos entre outubro de 1850 e setembro 1851 , como se vê na relação que segue" abaixo elencados pelo autor os beneficiados com os títulos:

Relação das datas de terras concedidas na Picada Santa Cruz, com declaração das datas dos titulos de concessão das pessoas que as obtiveram $e \quad d a$ quantidade de braças; [...] Em 24 de dezembro de 1850 - Felippe de Normann [uma área de 1/4 de légua quadrada ou 2.250.000 braças quadradas] (CUNHA, 1988, p. 77-78).

Depois de receber esta área de terras von Normann se envolveu na especulação de terras em outros lugares da Província, além da tentativa frustrada de colonizar as terras da Serra de São Martinho. 
"Normann ainda adquiriu outras concessões, no lugar denominado Carijo do João Almeida", conforme narra Christillino (2006, p. 111), “esta área, já explorada por ervateiros, seria rapidamente apropriada pela elite local, grileira e interessada no comércio de terras aos imigrantes".

\section{Uma fundação para a Colônia do Pinhal}

Observa-se na literatura estudada informações desencontradas sobre a data de fundação da Colônia do Pinhal, bem como uma associação da denominação desta à Colônia de Santa Maria da Boca do Monte, como se fossem a mesma. De acordo com Belém (2000 [1933], p. 187) Pinhal pertencia a Estação Colônia, $3^{\circ}$ distrito administrativo e judiciário de Santa Maria, o qual abrangia também Arroio Grande, São Marcos e Colônia Philippson. Como o autor elenca a Colônia judaica de Philippson fundada em 1904 inferimos que o distrito citado em que se encontrava Pinhal competia a uma configuração administrativa pertencente, "à época" em que Belém pesquisou, ou seja, a década de 1930, e não a década de $1850^{23}$. Se em 1833 surgiria o município de Cruz Alta com limites passando pelas terras de Itaara (MARTINS, 2012). Pela Lei Provincial n. 6 , de 17 novembro de 1837 foi criada aFreguesia de Santa Maria da Boca do Monte desligando-se da Capela Curada de Cachoeira para tornar-se Matriz (NICOLOSO, 2013, p. 37). Borin (2010, p. 24) esclarece as divisões eclesiásticas que tornaram Santa Maria freguesia:

Devido às divisões administrativoeclesiásticas que demarcaram o território de Santa Maria, em 1779, D. José Joaquim Mascaranhas Castel
Branco, bispo do Rio de Janeiro, invocou como padroeira da Freguesia Nossa Senhora da Conceição de Cachoeira à qual ficou subordinada à capela do Acampamento de Santa Maria da Boca do Monte até 17 de novembro de 1837, quando foi elevada à Freguesia. Em 1812, o Oratório de Santa Maria foi substituido por Capela Curada, em 1837, ano da criação da Freguesia de Santa Maria da Boca do Monte, pela Lei Provincial $n$. 6, de 17 novembro, o curato foi elevado à Paróquia, deixando de ser filiada à matriz de Cachoeira e, em 1910, foi elevada a Diocese. A Comissão Demarcadora de Limites da localidade aconteceu em 1797 e Santa Maria tornou-se municipio em 1858, sendo que, canonicamente, o povoado tornou-se Capela Curada em 1812.

$\mathrm{Na}$ cartografia as terras de Itaara, no caso, do Pinhal, pertenciam ao município de Cruz Alta a partir de 1850 conforme o mapa da divisão (Figura 1$)^{24}$. Isso realça, de alguma forma o motivo pelo qual von Normann inscreveu os colonos do Pinhal junto ao município de Cruz Alta no Mapa estatístico, territorial e agrícola da Colonia de Santa Maria da Boca do Monte.

É pertinente destacar que o problema da localização do Pinhal empurra-o para uma encruzilhada geográfica de pertencimento territorial: ora de Santa Maria, ora de São Martinho e ora de Cruz Alta. Embora tal correlação limítrofe seja relevante, logo se dissipa quando averiguamos o ano de fundação de colônia. Torna-se comum encontrarmos, mas não menos significativo, nas obras de imigração e colonização alemã quadros elencando as colônias, os respectivos municípios que as originaram, o tipo - oficial ou particular, o(s) fundador(es) e o ano de fundação.

\footnotetext{
${ }^{23}$ Sendo assim, fazemos uma ressalva sobre nossos trabalhos anteriores a esta pesquisa no qual escrevemos como Pinhal sendo parte do $3^{\circ}$ distrito de Santa Maria na década de 1850. O que não confere como estamos a apresentar nessa pesquisa.

${ }^{24}$ Tiago Costa Martins apresenta no seu website "Itaara em fotos e documentos" uma evolução geográfica através de mapas do território de Itaara pertencendo a Rio Pardo (1809), Cruz Alta (1850) e Santa Maria (1900). Disponível em: <http://itaaraemfotosedocumentos.blogspot.com.br/>. Acesso em: $08 / 09 / 2015$.
} 
Como consideramos Kroeff um dos organizadores da Colônia, juntamente com Jacob Albrecht, consideramos improvável que tais datas propostas por Pellanda sejam válidas. Haja vista que Miguel Kroeff, e o irmão Lourenço Kroeff, estavam desembarcando na Província em 15 de novembro de 1846 (LUZ, 2010, p. 33; RUPPENTHAL, 2000, p. 11). Outro ano sugestionado de fundação é proposto por Ruppenthal (2000, p. 11) que analisa os documentos de Autos de Legitimação de Posse e Cultura Efetiva ou de Morada Habitual - AHRS afirmando que "os nomes dos primeiros 'colonos' chegados no Pinhal, em cujas medições de terras constam a sua declaração de que ali se encontravam antes de 1853, podem até suscitar alguma dúvida inicial quanto ao estabelecimento da Colônia". Explica ainda o autor baseado em von Normann que "a colônia não poderia ter sido fundada em 1857, pois já existia há no mínimo cerca de dois anos, conforme a citação do próprio Normann. A data mais provável seria entre os anos de 1853 a 1855” (RUPPENTHAL, 2000, p. 11). A análise de Ruppenthal com a documentação arrolada é muito plausível.

Todavia, ainda o ano de 1857 suscita dúvidas o qual é endossado por Belém (2000[1933]), Beltrão (1979), Brenner (2007) e Martins (2008). Dentre os autores que explicita o porquê do ano de 1857, Brenner toma por base os estudos do viajante Avé-Lallemant (1997 [1858]) o qual conhece a Colônia do Pinhal em março de 1858 declarando que o empreendimento colonial alemão já tivera uma boa colheita em apenas seis meses de trabalho, logo o preparo das lavouras iniciou em setembro de 1857 (2007, p. 3). As palavras de Avé-Lallemant sobre o Pinhal são:

Como já disse, a região onde achava chama-se Pinhal. $O$ alemão acima referido comprara uma bela faixa de terra e mandara dividi-la em colonias. Onze famílias já se mudaram para ali e lançaram os fundamentos de uma colônia alemã, cuja prosperidade parecia garantida, não fosse a má vontade de vários proprietários vizinhos. Pois levantou-se até a opinião de que Kröef incluíra em sua medição terras pertencentes ao governo. Removida essa insegurança, a laboriosidade dos colonos e a fertilidade do solo conduzirão a um melhor futuro. Depois de seis meses de trabalho, diversas familias já tiveram uma boa colheita e venderam seus produtos a muito bom preço. Já foram montados, perto, dois curtumes e uma serraria, estando ambas as indústrias em plena atividade (1997 [1858], p. 47, grifo nosso).

De acordo com Brenner (2007, p. 3) “a serraria citada era, certamente, a que pertencera ao anterior proprietário, movida a roda d'água, e agora pertenceria a Jacob Albrecht" conforme consta na planta da Colônia do Pinhal feita pelo agrimensor Gustav von Normann a qual apresenta "ao sudoeste, junto ao arroio do Pinhal, o 'Engenho de Jacó Abrecht'”. Portanto, é importante acompanharmos o trajeto de Bello (1997 [1856], p. 42) que percorria a localidade do Pinhal, em 25 de agosto de 1856, diz que"na boca da estrada do Pinhal, ao sair aos campos de Cima da Serra, na casa e engenho de serrar do impertinente velho Manoel Alves, despedi-me das pessoas que me haviam acompanhado desde Santa Maria”. Manoel Alves havia vendido as terras a Jacob Albrecht, segundo escreve Pellanda (1925, p. 175): “Juntou-se-lhe depois Jacob Albrecht, continuando, dahi por deante, a se desenvolver o novo nucleo na mesma base de autonomia e liberdade, em terras compradas por aquelles [Kroeff e Albrecht] ao cirurgião Manoel Alves."

Portanto, se Manoel Alves permaneceu nas terras do Pinhal até agosto de 1856 , conforme o relado de Bello, e a datação de Avé-Lallemant, referente à organização da colônia era de "seis meses" anteriores a março de 1858 , pode-se inferir sobre tal indício que a 
fundação da Colônia do Pinhal ocorreu entre setembro de 1856 entre setembro de $1857 .^{26}$

Em suma, não se tem um marco fundador ou um registro que documente o início do assentamento da colonização alemã em Pinhal. Contudo, há fixação de uma "pedra memorial" 27 como homenagem dos descendentes da comunidade teuto-brasileira através da Igreja Evangélica de Confissão Luterana do Brasil (IECLB), localizada no Pinhal, em Itaara.Ao oferecer a homenagem as famílias pioneiras que iniciaram o núcleo germânico localo grupo étnico tem- sobretudo um referencial para sua memória coletiva.

\section{Referências bibliográficas}

AMSTAD, Theodor. Cem anos de germanidade no Rio Grande do Sul (1824-1924). Tradução de Arthur Blásio Rambo. São Leopoldo: Ed. da UNISINOS, 1999.

AVÉ-LALLEMANT, Robert. A viagem pela Província do Rio Grande do Sul (1858). In: MARCHIORI, José Newton C.; NOAL FILHO, Valter Antônio (Orgs.). Santa Maria: relatos e impressões de viagem. Santa Maria: Ed. da UFSM, 1997, p. 43-48.

BELÉM, João. História do Município de Santa Maria 1797/1933. 3. ed. Santa Maria: Editora da UFSM, 2000.

BELLO, Luiz Alves Leite de Oliveira. Diário de uma viagem no interior da Prov ${ }^{\mathrm{a}}$. de São Pedro em 1856. In: MARCHIORI, José Newton C.; NOAL FILHO, Valter Antônio (Orgs.). Santa Maria: relatos e impressões de viagem. Santa Maria: Ed. da UFSM, 1997, p. 39-42.

BELTRÃO, Romeu. Cronologia histórica de Santa Maria e do extinto município de São Martino 1787-1930. 2. ed. Canoas: La Salle, 1979.

BORIN, Marta Rosa. Por um Brasil católico: tensões e conflitos no campo religioso da República. São Leopoldo, Tese (Doutorado), Universidade do Vale do Rio dos Sinos, 2010.

BRENNER, José Antonio. Imigração Alemã: a saga dos Niederauer. Santa Maria: Ed. da UFSM, 1995.

BUBLITZ, Juliana. Forasteiros na floresta subtropical - notas para uma história ambiental da colonização alemã no Rio Grande do Sul. Campinas, Ambiente \& Sociedade, v. XI, n. 2, jul./dez. 2008, p. 323-340.

CASSOL, Fabricio Tironi. São Martinho: da desestruturação político-administrativa do município aos reflexos econômicos na região. Santa Maria, Monografia (Graduação), Centro Universitário Franciscano, 2012.

CHRISTILLINO, Cristiano Luís. A colonização e a grilagem no Rio Grande do Sul no século XIX. Mneme, v. 8, n. 22, jun./jul. de 2006, p. 96-123.

A política de terras do Estado Imperial na Província de São Pedro do Rio Grande do Sul. Escritas, v. 01, 2008, p. 83-104.

CUNHA, Jorge Luiz da. Os colonos alemães de Santa Cruz do Sul, Rio Grande do Sul 1849-1881.1988. Curitiba, Dissertação (Mestrado), Universidade Federal do Paraná, 1988.

$\overline{109-113 .}$

Brasileiros. In:

(Org.). Cultura alemã - 180 anos. Ed. bilíngue. Porto Alegre: Nova Prova, 2004b, p.

Imigração e Colonização Alemã. In: PICCOLO, Helga Iracema L.; PADOIN, Maria Medianeira (Dir.). Império. (Coleção História Geral do Rio Grande do Sul) v. II. Passo Fundo: Méritos, 2006, p. 279-300.

\footnotetext{
${ }^{26}$ Sobre as dificuldades na selva subtropical expostas por Bublitz (2008) refletimos sobre este curto período de trabalho na mata e a vivência para organizar uma colônia nos trópicos: enfrentar os perigos da fauna e da flora, derrubar a mata, separar a madeira, serrar, queimar o mato para ter solo para plantio (coivara) ou construir a casa e galpões, fazer a roçada, plantar e, por fim, colher. Não temos como certificar a (im)possibilidade disto.

${ }^{27}$ A pedra memorial fixada na entrada do Cemitério luterano, em Itaara, contém a seguinte descrição: "Homenagem da Igreja Evangélica de Confissão Luterana do Brasil (IECLB) aos colonizadores de Itaara (Pinhal), dezembro - 1857. Famílias: Jacob Adamy, Miguel Kroeff e Jacob Albrecht. Itaara 25 julho - 200[]. A diretoria".
} 
FISHER, Jacy Waldyr. Toponímia alemã no Rio Grande do Sul. In: ARENDT, Isabel Cristina; WITT, Marcos Antônio (orgs.). História, cultura e memória: 180 anos de imigração alemã. São Leopoldo; Oikos, 2005, p. 166-181.

FLORES, Ana Paula. Descanse em paz: testamentos e cemitério extramuros na Santa Maria de 1850 a 1900 . Porto Alegre, Dissertação (Mestrado), Pontifícia Universidade Católica do Rio Grande do Sul, 2006, p. 96.

GINZBURG, Carlo; PONI, Carlo. O nome e como: troca desigual no mercado historiográfico. In: A microhistória e outros ensaios. Rio de Janeiro: Bertrand Brasil, 1989, p. 169-178.

Sinais: raízes de um paradigma indiciário. In: . Mitos, emblemas, sinais: morfologia e história. São Paulo: Companhia das Letras, 1989. p. 143-179.

GIRON, Loraine S.; BERGAMASCHI, Heloisa E. Colônia: um conceito controverso. Caxias do Sul: EDUCS, 1996.

IOTTI, Luiza H (Org.). Imigração e colonização: legislação de 1747 a 1915. Porto Alegre: Assembleia Legislativa do Estado do RS. Caxias do Sul: EDUCS, 2001, p. 108.

KÜLZER, Gláucia Giovana L. de L. De Sacramento a Boca do Monte: a formação patrimonial de famílias de elite na Província de São Pedro (Santa Maria, RS, século XIX). São Leopoldo, Dissertação (Mestrado), Universidade do Vale do Rio dos Sinos, 2009, p. 52.

LEVI, Giovanni. Sobre a micro-história. In: BURKE, Peter (org.). A escrita da História - novas perspectivas. São Paulo: Ed. UNESP, 1992, p. 133-161.

LUZ, João H. Jacob Kroeff - Jacob Kroeff Filho - Jacob Kroeff Netto: o Hoteleiro, o Coronel, o Intendente - 1855 a 1966. Porto Alegre, Dissertação (Mestrado), Pontifícia Universidade Católica do Rio Grande do Sul, 2010.

MARTINS, Tiago C. (Org.). (Re)Pensar o desenvolvimento de Itaara: discussões acadêmicas em prol do município quatro estudos sobre história, geografia, economia e turismo. Itaara: Câmara Municipal de Vereadores de Itaara, 2008.

MATTOSO, José. A escrita da história: teoria e métodos. Lisboa: Editorial Estampa, 1988.

NICOLOSO, Fabrício R. Fazer-se elite em Santa Maria-RS: os imigrantes alemães entre estratégias políticas e sociais - 1830/1891. 2013. Santa Maria, Dissertação (Mestrado), Universidade Federal de Santa Maria, 2013.

; CUNHA, Jorge Luiz da. Os imigrantes alemães em Santa Maria: estratégias familiares e escândalos políticos no final do século 19. Disponível em: <http://www.eeh2012.anpuhrs.org.br/resources/ anais/18/1346357328_ARQUIVO_Textocompletoanpuh201297-2003.pdf>. Acesso em: 08/09/2014.

PELLANDA, Ernesto. A colonização germânica no Rio Grande do Sul. Porto Alegre: Globo, 1925.

PORTO, Aurélio. O trabalho alemão no Rio Grande do Sul. Porto Alegre: Santa Terezinha, 1934.

ROCHE, Jean. A colonização alemã e o Rio Grande do Sul. Porto Alegre: Globo, 1969. v. 1.

RUPPENTHAL, Paulo Roberto. A colônia alemã do Pinhal, século XIX: origens, formação e desenvolvimento. Santa Maria, Monografia (Graduação), Centro Universitário Franciscano, 2000.

SPOLAOR, Andréia Simone de O. A imigração russa-alemã na $4^{a}$ colônia de imigração italiana (1877-1890). Santa Maria, Monografia (Graduação), Centro Universitário Franciscano, [s.d.].

WEIMER, Günter. A arquitetura. Porto Alegre: UFRGS, 1992.

. Georg Karl Phillip Theodor von Normann. In: . Arquitetos e construtores do rio-grandenses na colônia e no império. Santa Maria: Ed. da UFSM, 2006, p. 146-154.

Gustav Adolf von Normann. In: . Arquitetos e construtores do rio-grandenses na colônia e no império. Santa Maria: Ed. da UFSM, 2006, p. 154-155.

ZARTH, Paulo Afonso. Do arcaico ao moderno: o Rio Grande do Sul agrário do século XIX. Ijuí: Editora UNIJUI, 2002. 


\section{Websites}

MARTINS, Tiago C. Itaara em fotos $e$ documentos. Disponível em: $<$ http:// itaaraemfotosedocumentos.blogspot.com.br/>. Acesso em: 08 set. 2015.

\section{Fontes}

Arquivo Municipal da Câmara de Santa Maria - AMCVSM:

Arquivo Histórico do Rio Grande do Sul - AHRS:

Arquivo Histórico Municipal de Santa Maria - AHMSM:

BRENNER, José Antonio. Pinhal - 150 anos - Itaara. Folheto 4f. [s.1.]: [s.n], [2007a].

BRENNER, José Antonio. Os 150 anos da Colônia Pinhal. Jornal A Razão, Santa Maria, 21 de maio de 2007b, p. 6. BRENNER, José Antonio. As famílias pioneiras do Pinhal. Jornal A Razão, Santa Maria, 21 de maio de 2007 c, p. 7. BRENNER, José Antonio. O Sesquicentenário do berço de Itaara. Jornal A Razão, Santa Maria, 14 de nov. 2007d, Caderno Segundo A Razão, [s.p.].

Colonização. Relatório de Felipe de Normann - 1 de maio de 1858. AHRS - caixa 35 - maço 65.

Colonização. Mapa estatístico, territorial e agrícola da Colônia de Santa Maria da Boca do Monte. Relatório de Felipe de Normann - 1858. AHRS - caixa 35 - maço 65.

Acervo Pessoal José Antonio Brenner - APJAB:

Livro I de Atas 1 (1858-1864) - AMCVSM. fls. 107v; 108; e 108v. 